\title{
Colorectal cancer survival among Ministry of National Guard-Health Affairs (MNG-HA) population 2009-2017: retrospective study
}

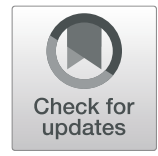

Mesnad Alyabsi ${ }^{1,2}$, Fouad Sabatin ${ }^{3}$, Majed Ramadan ${ }^{1,2^{*}}$ and Abdul Rahman Jazieh ${ }^{3}$

\begin{abstract}
Background: Colorectal cancer (CRC) is the most diagnosed cancer among males and third among females in Saudi Arabia, with up to two-third diagnosed at advanced stage. The objective of our study was to estimate CRC survival and determine prognostic factors.

Methods: Ministry of National Guard- Health Affairs (MNG-HA) registry data was utilized to identify patients diagnosed with CRC between 2009 and 2017. Cases were followed until December 30th, 2017 to assess their one-, three-, and five-year CRC-specific survivals. Kaplan-Meier method and Cox proportional hazard models were used to assess survival from CRC.

Results: A total of 1012 CRC patients were diagnosed during 2009-2017. Nearly, one-fourth of the patients presented with rectal tumor, $42.89 \%$ with left colon and $33.41 \%$ of the cases were diagnosed at distant metastasis stage. The overall one-, three-, and five-year survival were 83,65 and $52.0 \%$, respectively. The five-year survival was 79.85\% for localized stage, $63.25 \%$ for regional stage and $20.31 \%$ for distant metastasis. Multivariate analyses showed that age, diagnosis period, stage, nationality, basis of diagnosis, morphology and location of tumor were associated with survival.

Conclusions: Findings reveal poor survival compared to Surveillance, Epidemiology, and End Results (SEER) population. Diagnoses at late stage and no surgical and/or perioperative chemotherapy were associated with increased risk of death. Population-based screening in this population should be considered.
\end{abstract}

Keywords: Colorectal cancer (CRC), Registry, SEER, Survival, Saudi Arabia

\section{Introduction}

Worldwide, colorectal cancer (CRC) is the third most common cancer with more than 1.9 million new cases were diagnosed in 2020 [1]. Age standardized incidence rates are highest in developed countries such as Australia, New Zealand, Europe and North America due to urbanization and high-calorie diet; whereas incidence

\footnotetext{
* Correspondence: ramadhanma@ngha.med.sa

${ }^{1}$ Population Health Research Department, King Abdullah International Medical Research Center, P.O. Box 22490, Riyadh 11426, Saudi Arabia

${ }^{2}$ King Saud bin Abdulaziz University for Health Sciences, P.O. Box 22490, Riyadh 11426, Saudi Arabia

Full list of author information is available at the end of the article
}

rates are lowest in Africa and developing Asian countries and the Gulf Cooperation Council (GCC) [1]. Although incidence rates have been declining in Western countries, due to systematic screening programs which aim to detect and remove precancerous polyps, the rates have been increasing considerably in GCC countries. This is probably due to increasing prevalence of CRC risk factors such as lack of physical activities, smoking and unhealthy diet, along with the lack of organized screening programs.

More than 935,000 CRC deaths were reported globally in 2020 [1]. Unlike developed countries where mortality

C C The Author(s). 2021 Open Access This article is licensed under a Creative Commons Attribution 4.0 International License, which permits use, sharing, adaptation, distribution and reproduction in any medium or format, as long as you give appropriate credit to the original author(s) and the source, provide a link to the Creative Commons licence, and indicate if changes were made. The images or other third party material in this article are included in the article's Creative Commons licence, unless indicated otherwise in a credit line to the material. If material is not included in the article's Creative Commons licence and your intended use is not permitted by statutory regulation or exceeds the permitted use, you will need to obtain permission directly from the copyright holder. To view a copy of this licence, visit http://creativecommons.org/licenses/by/4.0/ The Creative Commons Public Domain Dedication waiver (http://creativecommons.org/publicdomain/zero/1.0/) applies to the data made available in this article, unless otherwise stated in a credit line to the data. 
rates have been decreasing, the rates are increasing in developing countries. The declining mortality rates in developed countries pertain to a combination of early detection efforts, where CRC is diagnosed at early curable stage, and effective treatments. The increasing mortality rates in developing countries that coincide with increasing incidence reflects increased prevalence of CRC risk factors, lack of screening at the population level, and treatment of cases most likely presented with advance diseases [1-4].

In Saudi Arabia, CRC is the most common cancer in Saudi males and the third among Saudi females $[5,6]$, with an age standardized incidence rate tripled since the establishment of cancer registry in 1994 [6, 7]. In 2017, the age standardized rates per 100,000 were 10.6 for males and 8.2 for females, with highest rates reported in Riyadh region [6]. The increasing incidence rate is the highest among the GCC countries because of the increasing adoption of sedentary lifestyle, smoking and Western cuisine [4]. Despite a well-established healthcare system, and the initiating of national CRC screening guidelines, up to $73 \%$ of CRC tumors diagnosed at late stage, a reflection of lack of early CRC detection programs $[3,5,6]$.

The World Health Organization (WHO) estimated mortality rates in 2016 to be 10 per 100,000 among Saudi males and 7 per 100,000 among females [8]. While mortality data are unavailable from Saudi Arabia, prior studies examined CRC survival among Saudi population. For example, two studies investigated the overall survival between 1994 and 2004 and showed that the 5-year CRC survival was $44.6 \%[9,10]$. Another prospective study found that the median survival time among CRC patient to be 54 months [11]. However, previous research lack important prognostic factors (e.g., tumor morphology, basis of diagnosis and marital status) [10], or failed to report survival after adjustments of prognostic factors $[9,11]$.

Numerous factors influence and predict the outcome of CRC. Among studied factors are: age, socioeconomic (SES), comorbidities, tumor characteristics such as location, stage at diagnosis and degree of differentiation and treatment [12]. For instance, tumors diagnosed at early stage and those that are well-differentiated have better survival than their counterparts. Likewise, tumors with no lymphovascular invasion or distant metastases have better prognosis than those with invasion or metastases.

In view of that, current study was designed to elucidate factors associated with CRC survival among MNGHA population. The findings of this study are intended to bring importance to the most diagnosed cancer in Saudi males. Hence, interventions may be planned, and policy devised to provide high-quality cancer care and detect disease when survival are highest.

\section{Methods}

\section{Data sources}

The current study is a retrospective cohort study using data from the (MNG-HA) Cancer Registry. The registry, which was established in 1994, collect information about cancer patients' demographic information, clinical characteristics including type of cancers, their location and extent at the time of diagnosis. The registry captures all cases diagnosed and treated at King Abdulaziz Medical City (KAMC) in Riyadh.

Follow-up information is captured in the data at each visit including patients' last contact date. Information on vital status is obtained annually through contacting patients or next of kin, and date and cause of death if dead are obtained from next of kin.

\section{Study population Identification of patients}

All individuals eligible for analysis were aged $\geq 18$ years diagnosed with a first primary invasive, malignant colorectal cancer International Classification of Diseases (ICD) (ICD-10 C18-C20) between 2009 and 2017, who were resident in Saudi Arabia and registered in MNG-HA hospitals system with follow-up time started at the date of CRC diagnosis in the registry and ended on the date of death, date of last contact or when study ended on December 31, 2017 whichever came first. The MNG-HA population include military service personnel and their dependents, members of civilian workforce and students from the MNG-HA related healthcare system. The population (>328,000 individuals) is served by tertiary care hospitals and four main primary and secondary care clinics. The oncology center at KAMC is a major oncology center in Riyadh region with estimated population of 8.2 million individuals. Approximately 30\% of all cancer cases in Saudi Arabia were treated at KAMC oncology center in Riyadh. There were 1017 individuals diagnosed with CRC between years 20092017. Of 1017 eligible patients, 5 (0.5\%) were excluded due to unknown survival status, admission or contact dates.

\section{Study variables \\ Patient and tumor characteristics}

Patient demographics including age at diagnosis, gender, marital status and nationality were all extracted from electronic health records. Clinical variables such as tumor's topography, morphology, treatment (surgery, radiotherapy and/or chemotherapy), grade, extent and basis of diagnosis, were derived from pathology reports and/or surgical specimens and were coded using (ICD-10 C18-C20). 
The anatomic tumor locations were categorized according to the ICD for Oncology-third edition topography as follow: right colon (i.e., cecum, ascending colon, hepatic flexure of colon and transverse colon), left colon (i.e., splenic flexure of colon, descending colon, and sigmoid), colon not otherwise specified (NOS) and rectum (rectosigmoid junction and rectum) [13-15].

SEER Summary Staging of localized, regional, and distant groups was used in this study [16].

\section{Outcome variable}

CRC-specific survivals were determined from registry records of survival time and the ascertainment of vital status. Follow-up time started at the date of CRC diagnosis in the registry and ended on the date of death, date of last contact or when study ended on December 31, 2017 whichever came first. To allow for 5-years of survival estimates, we restricted the population to patients diagnosed with CRC anytime up to December 31, 2017. We excluded patients with follow-up of $<1$ months [17]. Completeness of follow-up was computed at each time interval using Clark's Completeness Index (CCI) as well as a simplified person-time (SPT) method [17-19]. The resulting CCI and SPT were 72.38 and $80.64 \%$, respectively.

\section{Statistical analysis}

The demographic and clinical characteristics were assessed across three periods (2009-2011, 2012-2014 and 2015-2017) using Cochran-Armitage or CochranMantel-Haenszel tests, where appropriate. The 1-, 3and 5-year CRC-specific survival were estimated using Kaplan-Meier product limit method and differences between curves were assessed using log-rank test. The data was right-censored, there was no patient censored alive before the end of the complete follow-up time, thus all censored subjects were due to death only. Cox proportional hazards regression models were used to assess the univariate and multivariate association between CRC-specific survival time and covariates. We assessed the proportional hazard assumption using Schoenfeld residuals. Variables included in the multivariate regression model were diagnosis period, age, gender, marital status, nationality, stage at diagnosis, tumor's topography, morphology, grade, surgery, chemotherapy, radiotherapy, and basis of diagnosis (histology of primary vs. metastasis). We assessed interaction between all covariates and found a significant interaction between diagnosis period and basis of diagnosis at the univariate analysis, but the interaction was insignificant when added to the multivariate model and was dropped from the final model.
Backward elimination was used during multivariate analysis to retain all variables with $P<0.20$.

All statistical tests were 2-sided, and findings were considered statistically significant at $P<.05$. All analyses were conducted using SAS statistical software version 9.4 (SAS Institute Inc. Cary, NC).

\section{Results}

The application of the eligibility criteria resulted in a cohort of 1012 patients diagnosed with CRC between 2009 and 2017. Tables 1, and 2 show the demographic and clinical characteristics of the study population. Overall, there has been a significant increase in the diagnosis of CRC between 2009 and 2011 28.46\% and 2012-2014 35.47\%, however this increase has declined in 2015-2017 32.51\%. There was 57.51\% men, $74.51 \%$ married individuals and $92.49 \%$ Saudis diagnosed with CRC. Single individuals represent 5.4\% of the CRC population. While $42.89 \%$ of colon cancer patients were diagnosed with left-side tumor, about one-fourth of CRC patients were diagnosed with rectal tumor and $83.1 \%$ presented with stage III or IV tumors. The most diagnosed tumors were a histology of adenocanrcinoma of primary tumor that were moderately differentiated.

By the end of follow-up, 275 patients censored due to death, 274 deaths were due to CRC and 1 was due to other causes. No patient was censored alive before the end of the complete follow-up time. The 1-, 3- and 5year CRC survival were 83.09 (95\% CI: 80.44, 85.41), 65\% (95\% CI: $61.39,65.77)$ and 52\% (95\% CI: 46.35 , 57.24), respectively (Table 2). Male, single individuals and those who are non-Saudi have higher 1-year survival than their counterparts, while married and Saudis have higher 3 and 5 -years survival than their counterparts. The 1-year survival has improved slightly during the latest period (2015-2017) compared to prior periods (Table 2).

According to patient's clinical characteristics, patients with a tumor located at left colon, those with grade moderately differentiated tumors or patients presented with localized tumor of a primary origin and adenocarcinoma in nature were more likely to have higher survival (Table 3). Survival decreases significantly with the increased stage at diagnosis (the 5-year survival of localized, regional and distant metastatic tumors were 79.85, 63.25 and 20.31\%, respectively) (Table 3, and Fig. 1). Patients who have been treated with surgery and perioperative chemotherapy have significantly higher survival relative to those who did not treat with it (Table 3).

Table 4 shows the results of univariate and multivariate cox regression analyses. Patients diagnoses at younger age $(<=40)$ and older age ( $>70$ years), 
Table 1 Demographic and Clinical Characteristics by Diagnosis Period, MNGHA 2009-2017ª

\begin{tabular}{|c|c|c|c|c|c|c|c|c|c|}
\hline \multirow{3}{*}{$\begin{array}{l}\text { Characteristics } \\
\text { Total }\end{array}$} & \multicolumn{2}{|l|}{ Total } & \multicolumn{6}{|c|}{ Diagnosis period } & \multirow{3}{*}{$P$} \\
\hline & \multirow{2}{*}{$\begin{array}{l}\mathbf{N}^{\mathbf{d}} \\
1012\end{array}$} & \multirow{2}{*}{$\begin{array}{l}\%, \text { SD } \\
100\end{array}$} & \multicolumn{2}{|c|}{$2009-2011$} & \multicolumn{2}{|c|}{ 2012-2014 } & \multicolumn{2}{|c|}{$2015-2017$} & \\
\hline & & & 288 & 28.46 & 395 & 35.47 & 329 & 32.51 & \\
\hline Age (years) & & & & & & & & & $0.0012^{b}$ \\
\hline Mean (SD) & 68.03 & 14.39 & 69.65 & 14.31 & 69.19 & 14.22 & 65.21 & 14.31 & \\
\hline$<=40$ & 40 & 3.95 & 8 & 2.78 & 14 & 3.54 & 18 & 5.47 & \\
\hline $41-50$ & 68 & 6.72 & 13 & 4.51 & 20 & 5.06 & 35 & 10.64 & \\
\hline $51-60$ & 186 & 18.38 & 48 & 16.67 & 72 & 18.23 & 66 & 20.06 & \\
\hline $61-70$ & 288 & 28.46 & 92 & 31.94 & 102 & 25.82 & 94 & 28.57 & \\
\hline $71-80$ & 237 & 23.42 & 60 & 20.83 & 105 & 26.58 & 72 & 21.88 & \\
\hline$>=81$ & 193 & 19.07 & 67 & 23.26 & 82 & 20.76 & 44 & 13.37 & \\
\hline \multicolumn{10}{|l|}{ Gender } \\
\hline Female & 430 & 42.49 & 127 & 40.51 & 161 & 40.76 & 142 & 43.16 & 0.65 \\
\hline Male & 582 & 57.51 & 161 & 59.49 & 234 & 59.24 & 187 & 56.83 & \\
\hline Marital status & & & & & & & & & 0.44 \\
\hline Single & 55 & 5.43 & 15 & 5.21 & 23 & 5.82 & 17 & 5.17 & \\
\hline Married & 748 & 74.91 & 224 & 77.78 & 294 & 74.43 & 240 & 72.95 & \\
\hline Widowed/divorced & 57 & 5.63 & 15 & 5.21 & 17 & 4.30 & 25 & 7.60 & \\
\hline Unknown & 142 & 14.03 & 34 & 11.89 & 61 & 15.44 & 47 & 14.29 & \\
\hline Nationality & & & & & & & & & 0.36 \\
\hline Non-Saudi & 76 & 7.51 & 21 & 2.08 & 35 & 3.46 & 20 & 1.98 & \\
\hline Saudi & 936 & 92.49 & 267 & 97.92 & 360 & 96.54 & 309 & 98.02 & \\
\hline Tumor Site & & & & & & & & & 0.002 \\
\hline Right colon & 184 & 18.18 & 42 & 14.58 & 67 & 16.96 & 75 & 22.79 & \\
\hline Left colon & 434 & 42.89 & 121 & 42.01 & 174 & 44.05 & 139 & 42.25 & \\
\hline Colon-non specified & 160 & 15.18 & 62 & 21.53 & 65 & 16.46 & 33 & 10.03 & \\
\hline Rectum & 234 & 23.12 & 63 & 21.87 & 89 & 22.53 & 82 & 24.92 & \\
\hline Tumor Morphology & & & & & & & & & $0.78^{c}$ \\
\hline Adenocarcinoma (AC), NOS & 854 & 84.39 & 238 & 82.64 & 339 & 85.82 & 277 & 84.19 & \\
\hline Mucinous AC & 63 & 6.23 & 18 & 6.25 & 23 & 5.82 & 22 & 6.69 & \\
\hline Mucin-producing AC & 12 & 1.19 & 4 & 1.39 & 2 & 0.51 & 6 & 1.82 & \\
\hline Signet ring cell carcinoma & 14 & 1.38 & 5 & 1.74 & 7 & 1.77 & 2 & 0.61 & \\
\hline AC in villous/tubuvillous adenoma & 16 & 1.58 & 6 & 2.08 & 5 & 1.27 & 5 & 1.52 & \\
\hline Others & 53 & 5.34 & 17 & 5.90 & 19 & 4.81 & 17 & 5.17 & \\
\hline Tumor grade & & & & & & & & & 0.48 \\
\hline Well differentiated & 33 & 3.26 & 12 & 4.17 & 9 & 2.28 & 12 & 3.65 & \\
\hline Moderately differentiated & 774 & 76.48 & 222 & 77.08 & 296 & 74.94 & 256 & 77.81 & \\
\hline Poorly differentiated/Anaplastic & 67 & 6.62 & 15 & 5.21 & 29 & 7.34 & 23 & 6.99 & \\
\hline Unknown & 138 & & & & & & & & \\
\hline Stage at diagnosis & & & & & & & & & 0.0002 \\
\hline Localized & 227 & 22.43 & 72 & 18.23 & 111 & 28.10 & 44 & 13.37 & \\
\hline Regional & 441 & 40.61 & 111 & 37.63 & 146 & 36.96 & 154 & 46.81 & \\
\hline Distant metastasis & 338 & 33.41 & 96 & 33.33 & 127 & 32.15 & 115 & 34.95 & \\
\hline Unknown & 36 & 3.56 & 9 & 3.13 & 11 & 2.78 & 16 & 4.86 & \\
\hline Basis of diagnosis & & & & & & & & & $0.02^{c}$ \\
\hline Histology of primary & 972 & 96.05 & 275 & 95.49 & 381 & 96.46 & 316 & 96.04 & \\
\hline Histology of metastases & 28 & 2.77 & 8 & 2.78 & 9 & 2.28 & 11 & 3.34 & \\
\hline
\end{tabular}


Table 1 Demographic and Clinical Characteristics by Diagnosis Period, MNGHA 2009-2017 ${ }^{\mathrm{a}}$ (Continued)

\begin{tabular}{|c|c|c|c|c|c|c|c|c|c|}
\hline \multirow{3}{*}{$\frac{\text { Characteristics }}{\text { Others }}$} & \multicolumn{2}{|c|}{ Total } & \multicolumn{6}{|c|}{ Diagnosis period } & \multirow{3}{*}{$P$} \\
\hline & \multirow{2}{*}{$\begin{array}{l}\mathbf{N}^{\mathbf{d}} \\
12\end{array}$} & \multirow{2}{*}{$\begin{array}{l}\%, \text { SD } \\
1.19\end{array}$} & \multicolumn{2}{|c|}{$2009-2011$} & \multicolumn{2}{|c|}{$2012-2014$} & \multicolumn{2}{|c|}{$2015-2017$} & \\
\hline & & & 5 & 1.74 & 5 & 1.27 & 2 & 0.61 & \\
\hline & & & & & & & & & 0.65 \\
\hline \multicolumn{10}{|l|}{ Surgery } \\
\hline Yes & 426 & 42.09 & 179 & 62.15 & 157 & 39.75 & 90 & 27.36 & \\
\hline No & 586 & 57.91 & 109 & 37.85 & 238 & 60.25 & 239 & 72,64 & \\
\hline Chemotherapy & & & & & & & & & $<0.0001$ \\
\hline Yes & 411 & 40.61 & 180 & 62.5 & 172 & 43.54 & 79 & 24.01 & \\
\hline No & 601 & 59.39 & 108 & 37.5 & 243 & 56.46 & 250 & 75.99 & \\
\hline Radiotherapy & & & & & & & & & 0.007 \\
\hline Yes & 95 & 9.39 & 40 & 13.89 & 32 & 8.10 & 23 & 6.99 & \\
\hline No & 917 & 90.61 & 248 & 86.11 & 363 & 91.99 & 306 & 93.01 & \\
\hline
\end{tabular}

${ }^{a}$ Data represent colorectal cancer patients registered in MNG-HA hospitals system between 1 January 2009 and 31 December 2017

b $P$-values refer to comparisons between years range using Chi-square test

${ }^{\mathrm{C}} \mathrm{P}$-values refer to comparisons between marital status groups using Fisher exact test

d "N" total sample size

Table 2 CRC-specific Survival by Patients' Demographic Characteristics (2009-2017)

\begin{tabular}{|c|c|c|c|c|c|c|c|}
\hline \multirow[b]{2}{*}{ Overall } & \multicolumn{3}{|c|}{ 1-year } & \multicolumn{2}{|c|}{ 3-year } & \multicolumn{2}{|c|}{ 5-year } \\
\hline & $\bar{N}$ & $\%$ & $(95 \% \mathrm{Cl})$ & $\%$ & $(95 \% \mathrm{Cl})$ & $\%$ & $(95 \% \mathrm{Cl})$ \\
\hline & 1012 & 83.09 & $(80.44,85.41)$ & 65.0 & $(61.39,65.77)$ & 52.0 & $(46.35,57.24)$ \\
\hline \multicolumn{8}{|l|}{ Diagnosis period ${ }^{*}$} \\
\hline 2009-2011 & 288 & 83.76 & $(78.79,87.66)$ & 65.17 & $(59.88,72.16)$ & 51.89 & $(44.44,58.82)$ \\
\hline 2012-2014 & 395 & 81.16 & $(76.61,84.91)$ & 62.91 & $(54.87,69.91)$ & - & - \\
\hline 2015-2017 & 329 & 84.08 & $(79.01,88.02)$ & 65.16 & $(48.59,77.56)$ & - & - \\
\hline \multicolumn{8}{|l|}{ Age } \\
\hline$\leq 40$ & 40 & 77.28 & $(59.33,88.05)$ & 61.47 & $(37.19,78.71)$ & 30.73 & $(1.91,70.36)$ \\
\hline $41-50$ & 68 & 94.82 & $(84.75,98.31)$ & 65.77 & $(46.36,79.59)$ & 50.74 & $(27.00,73.25)$ \\
\hline $51-60$ & 186 & 86.71 & $(80.26,91.17)$ & 68.57 & $(59.45,80.44)$ & 60.28 & $(43.75,73.36)$ \\
\hline $61-70$ & 288 & 89.87 & $(85.98,93.96)$ & 69.61 & $(61.35,76.44)$ & 63.41 & $(53.65,71.64)$ \\
\hline $71-80$ & 237 & 79.27 & $(73.00,84.24)$ & 67.17 & $(58.72,74.26)$ & 46.17 & $(33.91,57.59)$ \\
\hline$\geq 81$ & 193 & 67.66 & $(59.83,74.30)$ & 47.40 & $(37.27,56.85)$ & 35.91 & $(24.37,57.56)$ \\
\hline \multicolumn{8}{|l|}{ Gender } \\
\hline Female & 430 & 82.26 & $(78.05,84.93)$ & 61.34 & $(54.80,67.03)$ & 51.14 & $(43.01,58.68)$ \\
\hline Male & 582 & 83.73 & $(80.16,86.71)$ & 67.83 & $(60.01,71.57)$ & 53.38 & $(45.32,67.78)$ \\
\hline \multicolumn{8}{|l|}{ Marital status ${ }^{*}$} \\
\hline Single & 55 & 90.58 & $(76.57,96.40)$ & 61.96 & $(31.07,82.19)$ & 24.78 & $(4.10,54.37)$ \\
\hline Married & 748 & 82.35 & $(79.23,85.05)$ & 65.43 & $(60.56,68.53)$ & 53.97 & $(47.77,59.76)$ \\
\hline Widowed/divorced & 57 & 80.54 & $(64.61,89.83)$ & 47.13 & $26.23,65.51)$ & - & - \\
\hline Unknown & 142 & 82.40 & $(74.55,88.02)$ & 63.82 & $(48.89,75.43)$ & 58.50 & $(41.19,72.32)$ \\
\hline \multicolumn{8}{|l|}{ Nationality ${ }^{*}$} \\
\hline Saudi & 936 & 82.52 & $(79.73,84.96)$ & 65.01 & $(60.61,67.89)$ & 52.54 & $(46.77,57.98)$ \\
\hline Non-Saudi & 76 & 88.31 & $(76.39,94.42)$ & 61.28 & $(37.06,78.53)$ & - & - \\
\hline
\end{tabular}

* Indicate no pateints alive to calcuate survival rate for survival year period

* Indicate no pateints alive to calcuate survival rate for survival year period 
Table 3 CRC-specific Survival by Patients' Clinical Characteristics (2009-2017)

\begin{tabular}{|c|c|c|c|c|c|c|c|}
\hline \multirow[b]{2}{*}{ Overall } & \multicolumn{3}{|c|}{ 1-year } & \multicolumn{2}{|l|}{ 3-year } & \multicolumn{2}{|c|}{ 5-year } \\
\hline & $\mathrm{N}$ & $\%$ & $(95 \% \mathrm{Cl})$ & $\%$ & $(95 \% \mathrm{Cl})$ & $\%$ & $(95 \% \mathrm{Cl})$ \\
\hline \multicolumn{8}{|l|}{ Tumor Site } \\
\hline Right colon & 184 & 81.16 & $(73.46,86.83)$ & 61.16 & $(49.09,69.06)$ & 48.66 & $(35.19,61.84)$ \\
\hline Left colon & 434 & 87.00 & $(83.09,90.06)$ & 69.61 & $(62.99,75.26)$ & 60.00 & $(51.38,67.68)$ \\
\hline Colon-non specified & 160 & 76.84 & $(69.98,82.33)$ & 60.85 & $(52.00,68.56)$ & 50.44 & $(41.94,59.81)$ \\
\hline Rectum & 234 & 82.94 & $(76.89,87.53)$ & 48.07 & $(29.00,64.83)$ & 20.61 & $(1.82,53.63)$ \\
\hline \multicolumn{8}{|l|}{ Tumor grade ${ }^{*}$} \\
\hline Well differentiated & 33 & 85.91 & $(66.52,94,44)$ & 55.75 & $(26.94,77.08)$ & 37.17 & $(12.44,62.51)$ \\
\hline Moderately differentiated & 774 & 87.48 & $(84.71,89.78)$ & 69.73 & $(64.71,74.18)$ & 57.51 & $(50.85,63.59)$ \\
\hline Poorly differentiated/Anaplastic & 67 & 62.48 & $(48.36,73.75)$ & 43.64 & $(26.65,59.47)$ & - & - \\
\hline Unknown & 138 & 66.22 & $(56.6,74.16)$ & 49.64 & $(38.16,61.11)$ & 34.64 & $(19.75,51.00)$ \\
\hline \multicolumn{8}{|l|}{ Stage at diagnosis ${ }^{*}$} \\
\hline Localized & 227 & 93.67 & $(89.33,96.29)$ & 86.12 & $(77.55,91.59)$ & 79.85 & $(68.31,87.56)$ \\
\hline Regional & 441 & 92.66 & $(89.46,94.92)$ & 77.92 & $(83.54,71.19)$ & 63.25 & $(53.11,71.78)$ \\
\hline Distant metastasis & 338 & 63.29 & $(57.36,68.63)$ & 44.33 & $(37.65,51.11)$ & 20.31 & $(12.96,28.82)$ \\
\hline Unknown & 36 & 69.44 & $(43.89,85.60)$ & 38.88 & $(14.67,62.82)$ & - & - \\
\hline \multicolumn{8}{|l|}{ Surgery } \\
\hline Yes & 426 & 92.63 & $(89.62,94.79)$ & 75.98 & $(71.24,80.77)$ & 62.78 & $(55.23,69.42)$ \\
\hline No & 586 & 74.25 & $(69.36,78.51)$ & 53.44 & $(46.23,61.12)$ & 40.09 & $(31.35,49.62)$ \\
\hline \multicolumn{8}{|l|}{ Chemotherapy } \\
\hline Yes & 411 & 90.74 & $(87.39,93.23)$ & 67.94 & $(61.71,73.38)$ & 52.92 & $(45.19,60.06)$ \\
\hline No & 601 & 77.17 & $(73.15,81.67)$ & 63.69 & $(57.38,69.33)$ & 55.08 & $(46.35,62.98)$ \\
\hline \multicolumn{8}{|l|}{ Radiotherapy } \\
\hline Yes & 95 & 87.81 & $(79.04,93.06)$ & 56.83 & $(33.31,74.79)$ & 38.97 & $(15.54,62.66)$ \\
\hline No & 917 & 82.31 & $(79.45,84.81)$ & 64.83 & $(61.37,68.92)$ & 54.04 & $(45.39,57.34)$ \\
\hline
\end{tabular}

* Indicate no pateints alive to calcuate survival rate for survival year period

* Indicate no pateints alive to calcuate survival rate for survival year period

patients presented with advanced stages (regional or distant metastasis), and patients have not treated with surgery and perioperative chemotherapy were all at increased risk of CRC mortality compared to their counterparts. Lastly, as displayed in Tables 4, and 5, demonstrate that 5-year CRC survival among SEER population is higher than those in MNG-HA considerably, except for metastatic 5-year CRC where MNG-HA shows better survival.

\section{Discussion}

As CRC is becoming a public health burden in Saudi Arabia, evinced by lack of screening and increased incidence and mortality [4], it is imperative to elucidate changes in survivorship and shed lights on determinants of poor survivals. While prior studies have investigated survival among Saudi population $[9,10,20]$, the determinants of survivals while accounting for potential covariates such as period of diagnosis, case mix, marital status, treatment, and other tumor characteristics has yet to be demonstrated. Additionally, given the poor 5-year survival among Saudi population relevant to other population (e.g., SEER), reporting survival at duration earlier than 5 years is crucial. In this retrospective cohort study, findings showed that there is no significant improvement in CRC-specific survival among MNGHA population during past decade and found that the 1-, and 3-, survival were 84.08 , and $65.16 \%$, respectively.

One of the major findings of this study was that almost two third of cases had relatively late stage at diagnosis (regional/distant). Considering that stage at diagnosis is the most prognostic factor for CRC outcome, it is alarming to see the increasing trends of regional and distant metastasis CRC over time, the proportion with stage (regional/distant) disease increased from 74.02 to $81.76 \%$. The increase in late 


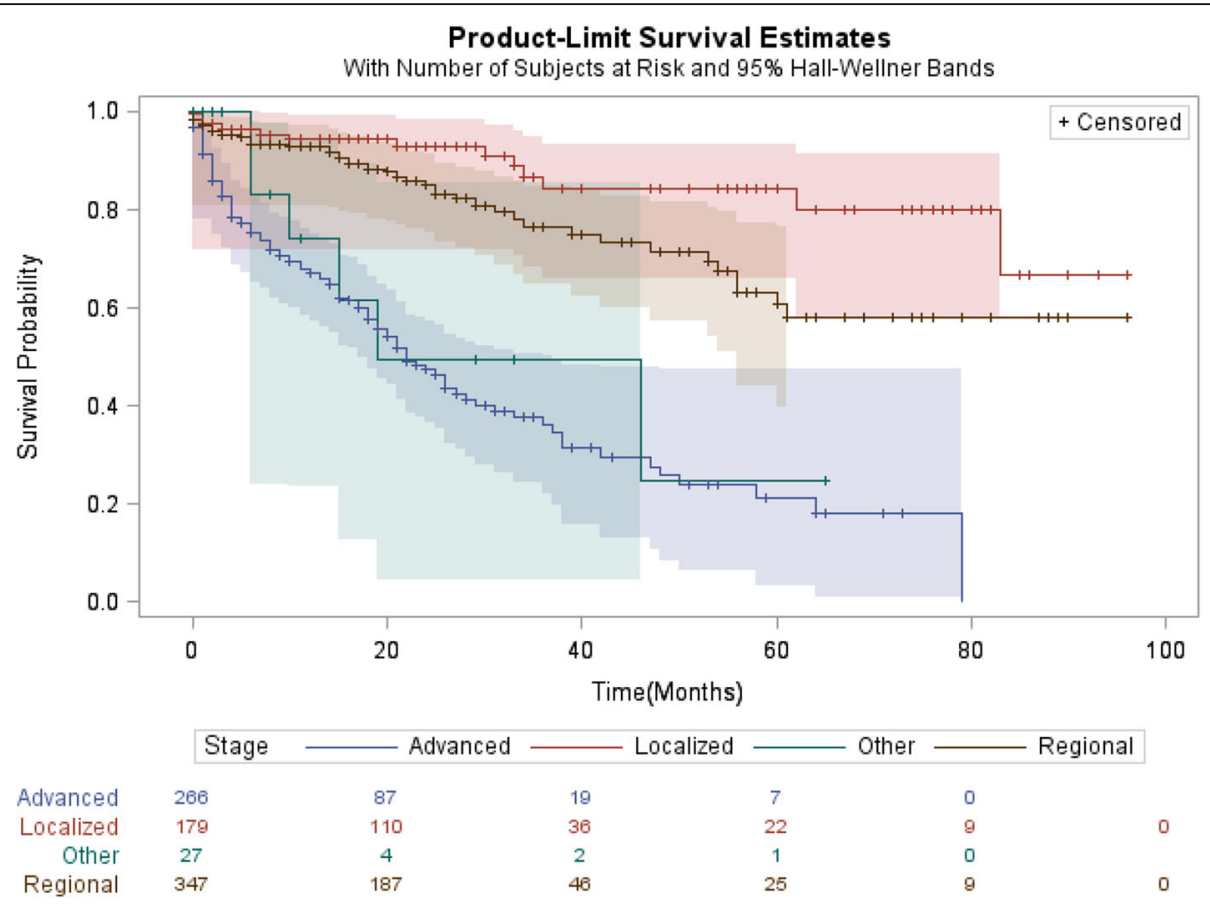

Fig. 1 Kaplan-Meier Survival Rate by Stage

cancer stages is likely to be as a result of improvements in imaging and diagnostic methods, resulting in a significant shift in stages over the years 20092017 in Saudi Arabia. Another possibility is lack of national data on the incidence of adenomatous polyps or the age groups in which the incidence surges, and absence of studies that evaluate effectiveness of different CRC screening test methodologies in Saudi Arabia [3]. While disparities in CRC survival in the US is partially driven by differences in SES and access to care, the disparities present in our study suggest otherwise. For example, given that the entire population at MNG-HA has equitable access to care, late stage at diagnosis $(31.79 \%$ reported here vs $22 \%$ in the US) in our population is primarily driven by lack of screening and potentially high prevalence of the Kristen Rat Sarcoma (KRAS) mutations in colorectal cancer, which is an indicator for poor effectiveness of certain treatments [21]. It is possible though some proportion of late-stage cases could have been developed due to delayed appointment, which should be investigated in future studies.

In multivariate analysis, we found that patients diagnosed at late cancer stage were more likely to die of their tumor compared to the early stages. Same has been found among SEER population and other studies across Europe [12, 22-26]. The prognosis of distant metastasis CRC is very poor since diagnosis at this stage is associated with high morbidity and mortality regardless of patient's characteristics.
Nonetheless, the only established method that has been associated with downstaging at the populationlevel is CRC screening [27], which is currently weak in Saudi Arabia despite recent calls for action [4, 9, 28 ]; hence the increasing percentage of distant metastasis tumors.

Over the study period, more than $80 \%$ of NGHA CRC patients have been treated with surgical resection of the primary tumor which has been the traditional approach to manage late CRC stage, or/and chemotherapy. In multivariate analysis, we found that patients treated with surgery or chemotherapy, have significant lower risk of death than those who did not use treatment. Similar results have previously been described [29-33]. Prolonged survival outcomes have been shown among CRC patients who were treated with both surgery and chemotherapy [29, 31]. Additionally, a meta-analysis conducted in 2015 emphasized on the survival benefits of chemotherapy alone, showing that oxaliplatin and capecitabine or infusional/bolus 5 -fluorouracil-based chemotherapy plus bevacizumab resulted in prolonged survival [31].

One of the strengths of the current study is the use of cancer registry of unique military population diagnosed with CRC and has never been studied. While the majority of MNG-HA are military personal, resembling the VA in the US, some are dependents who are white collar or students. Current study has nonetheless several limitations that should be noted. First, 
Table 4 Univariate and multivariate analysis of CRC-specific mortality with in 1,3 and 5 years since diagnosis during (2009-2017) ${ }^{a}$

\begin{tabular}{|c|c|c|c|c|c|}
\hline \multirow[t]{2}{*}{ Characteristics } & \multirow{2}{*}{$\begin{array}{l}\text { Total } \\
\mathrm{N}\end{array}$} & \multicolumn{3}{|c|}{ Univariate } & \multirow{2}{*}{$\begin{array}{l}\text { Multivariate } \\
95 \% \mathrm{Cl}\end{array}$} \\
\hline & & $\bar{b}$ aHR & $95 \% \mathrm{Cl}$ & aHR & \\
\hline \multicolumn{6}{|l|}{ Diagnosis period } \\
\hline 2009-2011 & 288 & - & - & - & \\
\hline 2012-2014 & 395 & 0.99 & $(0.74,1.31)$ & 0.91 & $(0.67,1.24)$ \\
\hline 2015-2017 & 329 & 0.96 & $(0.69,1.34)$ & 0.76 & $(0.52,1.12)$ \\
\hline \multicolumn{6}{|l|}{ Age } \\
\hline$<=40$ & 40 & 1.87 & $(1.09,3.47)$ & 1.72 & $(0.49,6.07)$ \\
\hline $41-50$ & 68 & 1.03 & $(0.58,1.54)$ & 0.73 & $(0.25,2.13)$ \\
\hline $51-60$ & 186 & 1.02 & $(0.67,1.54)$ & 0.79 & $(0.39,1.59)$ \\
\hline $61-70$ & 288 & - & - & - & - \\
\hline $71-80$ & 237 & 1.53 & $(1.09 .3 .5)$ & 1.29 & $(0.72,2.35)$ \\
\hline$>=81$ & 193 & 2.51 & $(1.8,3.5)$ & 1.36 & $(0.65,2.84)$ \\
\hline \multicolumn{6}{|l|}{ Gender } \\
\hline Female & 430 & 1.2 & $(0.92,1.48)$ & 1.002 & $(0.77,1.31)$ \\
\hline Male & 582 & - & - & & \\
\hline \multicolumn{6}{|l|}{ Marital status } \\
\hline Single & 55 & 0.91 & $(0.51,1.63)$ & 0.86 & $(0.45,1.61)$ \\
\hline Married & 748 & - & - & - & - \\
\hline Widowed/divorced & 57 & 1.41 & $(0.86,2.31)$ & 1.04 & $(0.6,1.81)$ \\
\hline Unknown & 142 & 0.91 & $(.068,1.43)$ & 0.92 & $(0.62,1.36)$ \\
\hline \multicolumn{6}{|l|}{ Nationality } \\
\hline Non-Saudi & 76 & 0.66 & $(0.37,1.18)$ & 0.65 & $(0.35,1.19)$ \\
\hline Saudi & 936 & - & - & - & - \\
\hline \multicolumn{6}{|l|}{ Tumor Site } \\
\hline Right colon & 184 & - & - & - & - \\
\hline Left colon & 434 & 0.77 & $(0.54,1.11)$ & 0.72 & $(0.49,1.04)$ \\
\hline Colon-non specified & 160 & 1.12 & $(0.76,1.62)$ & 0.88 & $(0.58,1.34)$ \\
\hline Rectum & 234 & 1.01 & $(0.68,1.51)$ & 0.98 & $(0.63,1.54)$ \\
\hline \multicolumn{6}{|l|}{ Tumor grade } \\
\hline Well differentiated & 33 & - & - & - & - \\
\hline Moderately differentiated & 774 & 0.73 & $(0.38,1.37)$ & 0.76 & $(0.38,1.49)$ \\
\hline (Poorly differentiated/Anaplastic)) & 67 & 1.98 & $(0.95,4.11)$ & 1.52 & $(0.69,3.31)$ \\
\hline Unknown & 138 & 1.7 & $(0.86,3.33)$ & 1.08 & $(0.51,2.75)$ \\
\hline \multicolumn{6}{|l|}{ Stage at diagnosis } \\
\hline Localized & 186 & - & - & - & - \\
\hline Regional & 362 & 1.89 & $(1.17,3.04)$ & 2.51 & $(2.51,4.13)$ \\
\hline Distant metastasis & 225 & 9.01 & $(5.79,14.71)$ & 11.43 & $(7.04,18.55)$ \\
\hline Unknown & 76 & 5.51 & $(2.71,11.49)$ & 4.87 & $(2.28,10.37)$ \\
\hline \multicolumn{6}{|l|}{ Basis of diagnosis } \\
\hline Histology of primary & 972 & - & - & - & - \\
\hline Histology of metastases & 28 & 4.89 & $(2.98,8.04)$ & 1.67 & $(0.92,3.04)$ \\
\hline Others & 12 & 6.42 & $(3.45,11.78)$ & 7.17 & $(0.92,3.04)$ \\
\hline
\end{tabular}


Table 4 Univariate and multivariate analysis of CRC-specific mortality with in 1,3 and 5 years since diagnosis during (2009-2017) ${ }^{a}$ (Continued)

\begin{tabular}{|c|c|c|c|c|c|}
\hline \multirow[t]{2}{*}{ Characteristics } & \multirow{2}{*}{$\begin{array}{l}\text { Total } \\
\mathrm{N}\end{array}$} & \multicolumn{3}{|c|}{ Univariate } & \multirow{2}{*}{$\begin{array}{l}\text { Multivariate } \\
95 \% \mathrm{Cl}\end{array}$} \\
\hline & & baHR & $95 \% \mathrm{Cl}$ & aHR & \\
\hline \multicolumn{6}{|l|}{ Morphology } \\
\hline Adenocarcinoma (AC), NOS & 854 & - & - & - & - \\
\hline Mucinous AC & 63 & 1.07 & $(0.64,1.78)$ & 0.78 & $(0.45,1.36)$ \\
\hline Mucin-producing AC & 12 & 1.62 & $(0.66,3.93)$ & 1.58 & $(0.63,3.94)$ \\
\hline Signet ring cell carcinoma & 14 & 5.07 & $(2.59,9.91)$ & 1.65 & $(0.75,3.61)$ \\
\hline AC in villous/tubuvillous adenoma & 16 & 0.071 & $(0.22,2.21)$ & 0.96 & $(0.30,3.08)$ \\
\hline Others & 53 & 1.68 & $(1.08,2.61)$ & 0.62 & $(0.33,1.21)$ \\
\hline \multicolumn{6}{|l|}{ Surgery } \\
\hline Yes & 426 & - & - & - & - \\
\hline No & 586 & 2.48 & $(1.92,3.19)$ & 1.36 & $(1.007,1.83)$ \\
\hline \multicolumn{6}{|l|}{ Chemotherapy } \\
\hline Yes & 411 & - & - & - & - \\
\hline No & 601 & 1.39 & $(1.07,1.74)$ & 1.65 & $(1.17,2.33)$ \\
\hline \multicolumn{6}{|l|}{ Radiotherapy } \\
\hline Yes & 95 & - & - & - & - \\
\hline No & 917 & 1.26 & $(0.82,1.93)$ & 0.79 & $(0.49,1.31)$ \\
\hline
\end{tabular}

${ }^{a}$ Data represent Saudi patients registered in the MNG-HA hospitals system between January 1, 2009, and December 31,2017

b aHR: Adjusted hazard ratio. Adjusted for all variables in Table 2

Bolded aHR indicates significant $p$-value

the findings should be generalizable to MNG-HA population or other similar population. Second, the reported CRC survival should be interpreted within the purview of CRC incidence and mortality rates in Saudi Arabia [34, 35]. Given the increasing rates of CRC incidence during the study period, and increased mortality $[4,8]$; although there is lack of mortality data, our findings suggest an increased disease burden. This lack of progress could be ameliorated through reduction in CRC risk factors, increased population-based screening and more effective stage-based treatment. Third, no treatment information was used in this study.

\section{Conclusion}

The current study characterized for the first time the CRC survival profile among MNG-HA population, revealing disproportionately poor survival compared to the US SEER data. Despite advancement in the Saudi healthcare, the fact that 5-year survival $(52 \%)$ is markedly lower than those reported among SEER population (65\%) and even lower than SEER's 10-year survival (58\%) presents a future challenge. To increase survival, it is imperative to adopt evident strategies at the population level that lead to downstaging such as CRC screening. The US National Polyp Study, for

Table 5 Five-year Colorectal Cancer Survival by Stage at Diagnosis in MNG-HA Compared to US SEER (2009-2017)

\begin{tabular}{|c|c|c|c|c|c|c|c|c|}
\hline & \multicolumn{2}{|l|}{ All stages } & \multicolumn{2}{|l|}{ Localized } & \multicolumn{2}{|l|}{ Regional } & \multicolumn{2}{|l|}{ Distance } \\
\hline & Survival (\%) & $95 \% \mathrm{Cl}$ & Survival (\%) & $95 \% \mathrm{Cl}$ & Survival (\%) & $95 \% \mathrm{Cl}$ & Survival (\%) & $95 \% \mathrm{Cl}$ \\
\hline \multicolumn{9}{|l|}{ Male } \\
\hline US SEER & 65.1 & $(64.8,65.3)$ & 88.6 & $(88.3,88.8)$ & 69.9 & $(69.4,70.4)$ & 13.0 & $(12.5,13.4)$ \\
\hline MNG-HA & 53.38 & $(45.32,67.78)$ & 81.57 & $(58.51,87.41)$ & 57.89 & $(43.44,69.89)$ & 19.08 & $(8.00,33.74)$ \\
\hline \multicolumn{9}{|l|}{ Female } \\
\hline US SEER & 66.5 & $(66.3,66.8)$ & 90.0 & $(89.7,90.3)$ & 71.4 & $(71.0,71.8)$ & 15.2 & $(14.7,15.7)$ \\
\hline MNG-HA & 51.14 & $(43.01,58.68)$ & - & - & 66.62 & $(51.08,78.22)$ & 21.96 & $(12.64,32.93)$ \\
\hline
\end{tabular}

US SEER (2003-2013) MNG-HA (2009-2017) 
instance, found that polypectomy result in 53\% reduction in CRC mortality and up to $76 \%$ reduction in the incidence of CRC.

\section{Acknowledgements}

The authors acknowledge the Oncology Department at MNG-HA for providing the data to Mr. Tabrez Pash.

\section{Authors' contributions}

All authors contributed equally to this manuscript. All authors read and approved the final manuscript.

\section{Funding}

Not applicable.

\section{Availability of data and materials}

The data are available from the Oncology Department, but restrictions apply to the availability of these data due to sensitive identifier that have been used in this study, which were used under license for the current study, and so are not publicly available. For further assistance please contact the corresponding author.

\section{Declarations}

\section{Ethics approval and consent to participate}

Committee of King Abdullah International Medical Research Center (KAIMRC) approved this study (RC20/383/R).

Biomedical ethics committee of King Abdullah International Medical Research Center (KAIMRC) approved this study (RC20/383/R).

All methods were performed in accordance with the relevant guidelines and regulations of KAIMRC.

Informed consent was obtained from all subjects 18 years or older, for subjects under 18, informed consent was obtained from a parent and/or legal guardian.

Informed consent was obtained from next of kin for deceased patients.

\section{Consent for publication}

Not applicable.

\section{Competing interests}

The authors declare that they have no competing interests.

\section{Author details \\ ${ }^{1}$ Population Health Research Department, King Abdullah International Medical Research Center, P.O. Box 22490, Riyadh 11426, Saudi Arabia. ${ }^{2}$ King Saud bin Abdulaziz University for Health Sciences, P.O. Box 22490, Riyadh 11426, Saudi Arabia. ${ }^{3}$ Oncology Department, Ministry of National Guard - Health Affairs, Riyadh, Saudi Arabia.}

Received: 24 March 2021 Accepted: 18 August 2021

Published online: 25 August 2021

\section{References}

1. Sung H, Ferlay J, Siegel R L, Laversanne M, Soerjomataram I, Jemal A, et al. Global cancer statistics 2020: GLOBOCAN estimates of incidence and mortality worldwide for 36 cancers in 185 countries. CA Cancer J Clin. 2021; 71(3):209-49.

2. World Health Organization: Cancer Country Profile 2020.

3. Alsanea N, Almadi MA, Abduljabbar AS, Alhomoud S, Alshaban TA, Alsuhaibani A, et al. National Guidelines for colorectal Cancer screening in Saudi Arabia with strength of recommendations and quality of evidence: tripartite task force from Saudi Society of Colon \& rectal surgery, Saudi gastroenterology association and Saudi oncology society. Ann Saudi Med. 2015;35(3):189-95. https://doi.org/10.5144/0256-4947.2015.189.

4. Alyabsi M, Alhumaid A, Allah-Bakhsh H, Alkelya M, Aziz MA. Colorectal cancer in Saudi Arabia as the proof-of-principle model for implementing strategies of predictive, preventive, and personalized medicine in healthcare. EPMA Journal. 2020 Mar;11(1):119-31. https://doi.org/10.1007/ s13167-019-00186-X.
5. Althubiti MA, Eldein MM. Trends in the incidence and mortality of cancer in Saudi Arabia. Saudi Med J. 2018:39(12):1259-62. https://doi.org/10.15537/ smj.2018.12.23348.

6. KFSHRC O.C.R.U: Tumor registry annual report 2015.

7. Bazarbashi S, Al Eid H, Minguet J. Cancer incidence in Saudi Arabia: 2012 data from the Saudi cancer registry. APJCP. 2017;18(9):2437-44. https://doi. org/10.22034/APJCP.2017.18.9.2437.

8. WorldHealth Organization: Cancer country profile - World Health Organization. 2014.

9. Alsanea N, Abduljabbar AS, Alhomoud S, Ashari LH, Hibbert D, Bazarbashi S. Colorectal cancer in Saudi Arabia: incidence, survival, demographics and implications for national policies. Ann Saudi Med. 2015;35(3):196-202. https://doi.org/10.5144/0256-4947.2015.196.

10. Al-Ahwal MS, Shafik YH, Al-Ahwal HM. First national survival data for colorectal cancer among Saudis between 1994 and 2004: what's next? BMC Public Health. 2013;13(1):1-6

11. Aldiab A, Al Khayal KA, Al Obaid OA, Alsheikh A, Alsaleh K, Shahid M, et al. Clinicopathological features and predictive factors for colorectal cancer outcome in the Kingdom of Saudi Arabia. Oncology. 2017;92(2):75-86. https://doi.org/10.1159/000450857.

12. Siegel RL, Miller KD, Fedewa SA, Ahnen DJ, Meester RG, Barzi A, et al. Colorectal cancer statistics, 2017. CA Cancer J Clin. 2017;67(3):177-93.

13. Murphy G, Devesa SS, Cross AJ, Inskip PD, McGlynn KA, Cook MB. Sex disparities in colorectal cancer incidence by anatomic subsite, race and age. Int J Cancer. 2011;128(7):1668-75. https://doi.org/10.1002/ijc.25481.

14. Lee YC, Lee YL, Chuang JP, Lee JC. Differences in survival between colon and rectal cancer from SEER data. PLoS One. 2013 Nov 12;8(11):e78709. https://doi.org/10.1371/journal.pone.0078709.

15. Chen WW, Hsieh MC, Charlton ME, Ruiz BA, Karlitz J, Altekruse SF, et al. Analysis of stage and clinical/prognostic factors for colon and rectal cancer from SEER registries: AJCC and collaborative stage data collection system. Cancer. 2014;120:3793-806. https://doi.org/10.1002/cncr.29056.

16. Young JL: SEER summary staging manual 2000: codes and coding instructions: National Cancer Institute, National Institutes of Health; 2001.

17. von Allmen RS, Weiss S, Tevaearai HT, Kuemmerli C, Tinner C, Carrel TP, et al. Completeness of follow-up determines validity of study findings: results of a prospective repeated measures cohort study. PLoS One. 2015 Oct 15;10(10):e0140817. https://doi.org/10.1371/journal.pone.0140817.

18. Xue X, Agalliu I, Kim MY, Wang T, Lin J, Ghavamian R, Strickler HD. New methods for estimating follow-up rates in cohort studies. BMC Med Res Methodol 2017;17(1):1-0.

19. Lark TG, Altman DG, De Stavola BL. Quantification of the completeness of follow-up. Lancet. 2002;359(9314):1309-10. https://doi.org/10.1016/501406736(02)08272-7.

20. Elsamany SA, Alzahrani AS, Mohamed MM, Elmorsy SA, Zekri JE, AlShehri AS, et al. Clinico-pathological patterns and survival outcome of colorectal cancer in young patients: western Saudi Arabia experience. Asian Pac J Cancer Prev. 2014;15(13):5239-43. https://doi.org/10.7314/A PJCP.2014.15.13.5239.

21. Bader T, Ismail A. Higher prevalence of KRAS mutations in colorectal cancer in Saudi Arabia: propensity for lung metastasis. Alexandria Journal of Medicine. 2014;50(3):203-9. https://doi.org/10.1016/j.ajme.2014.01.003.

22. Agüero F, Murta-Nascimento C, Gallén M, Andreu-García M, Pera M, Hernández C, et al. Colorectal cancer survival: results from a hospital-based cancer registry. Rev Esp Enferm Dig. 2012 Dec 1;104(11):572-7. https://doi. org/10.4321/S1130-01082012001100004.

23. Ramos M, Montano J, Esteva M, Barceló A, Franch P. Colorectal cancer survival by stage of cases diagnosed in Mallorca, Spain, between 2006 and 2011 and factors associated with survival. Cancer Epidemiol. 2016 Apr 1;41: 63-70. https://doi.org/10.1016/j.canep.2016.01.001.

24. De Angelis R, Sant M, Coleman MP, Francisci S, Baili P, Pierannunzio D, et al. Cancer survival in Europe 1999-2007 by country and age: results of EUROCARE-5—a population-based study. Lancet Oncol. 2014;15(1):23-34. https://doi.org/10.1016/S1470-2045(13)70546-1.

25. Howlander N, Noone A, Krapcho M. SEER cancer statistics review (CSR) 1975-2016. National Cancer Institute website seer cancer Published online 2019.

26. Allemani C, Rachet B, Weir HK, Richardson LC, Lepage C, Faivre J, Gatta G, Capocaccia R, Sant M, Baili P, Lombardo C. Colorectal cancer survival in the USA and Europe: a CONCORD high-resolution study. BMJ Open. 2013;3(9): e003055. 
27. Murphy CC, Sandler RS, Sanoff HK, Yang YC, Lund JL, Baron JA. Decrease in incidence of colorectal cancer among individuals 50 years or older after recommendations for population-based screening. Clin Gastroenterol Hepatol. 2017;15(6):903-9. https://doi.org/10.1016/j.cgh.2016.08.037.

28. Mosli MH, Al-Ahwal MS. Colorectal cancer in the Kingdom of Saudi Arabia: need for screening. Asian Pac J Cancer Prev. 2012;13(8):3809-13. https://doi. org/10.7314/APJCP.2012.13.8.3809

29. Simillis C, Kalakouti E, Afxentiou T, Kontovounisios C, Smith JJ, Cunningham $D$, et al. Primary tumor resection in patients with incurable localized or metastatic colorectal cancer: a systematic review and meta-analysis. World J Surg. 2019 Jul;43(7):1829-40. https://doi.org/10.1007/s00268-019-04984-2.

30. Clancy C, Burke JP, Barry M, Kalady MF, Coffey JC. A meta-analysis to determine the effect of primary tumor resection for stage IV colorectal cancer with unresectable metastases on patient survival. Ann Surg Oncol. 2014;21 (12):3900-8. https://doi.org/10.1245/s10434-014-3805-4.

31. Petrelli F, Coinu A, Ghilardi M, Cabiddu M, Zaniboni A, Barni S. Efficacy of oxaliplatin-based chemotherapy+ bevacizumab as first-line treatment for advanced colorectal cancer. Am J Clin Oncol. 2015;38(2):227-33. https://doi. org/10.1097/COC.0b013e3182a2d7b8.

32. Roder D, Karapetis CS, Wattchow D, Moore J, Singhal N, Joshi R, et al. Colorectal cancer treatment and survival: the experience of major public hospitals in South Australia over three decades. Asian Pac J Cancer Prev. 2015;16(6):2431-40. https://doi.org/10.7314/APJCP.2015.16.6.2431.

33. Lee KC, Ou YC, Hu WH, Liu CC, Chen HH. Meta-analysis of outcomes of patients with stage IV colorectal cancer managed with chemotherapy/ radiochemotherapy with and without primary tumor resection. Onco Targets Ther. 2016;9:7059-69. https://doi.org/10.2147/OTT.S112965.

34. Cho H, Mariotto AB, Schwartz LM, Luo J, Woloshin S. When do changes in cancer survival mean progress? The insight from population incidence and mortality. J Natl Cancer Inst Monogr. 2014;2014(49):187-97. https://doi.org/1 0.1093/jncimonographs/lgu014.

35. Mariotto AB, Noone AM, Howlader N, Cho H, Keel GE, Garshell J, et al. Cancer survival: an overview of measures, uses, and interpretation. J Nat Cancer Inst Monogr. 2014;2014(49):145-86. https://doi.org/10.1093/ jncimonographs/lgu024.

\section{Publisher's Note}

Springer Nature remains neutral with regard to jurisdictional claims in published maps and institutional affiliations.

Ready to submit your research? Choose BMC and benefit from:

- fast, convenient online submission

- thorough peer review by experienced researchers in your field

- rapid publication on acceptance

- support for research data, including large and complex data types

- gold Open Access which fosters wider collaboration and increased citations

- maximum visibility for your research: over $100 \mathrm{M}$ website views per year

At $\mathrm{BMC}$, research is always in progress.

Learn more biomedcentral.com/submissions 